\title{
Effect of Atrioventricular Dyssynchrony on Impella Hemodynamics: Mechanism and Its Clinical Implications
}

\author{
Raj Baljepallya , Hassan Tahir ${ }^{a}$,
}

\begin{abstract}
The physiologic importance of atrial systole and atrioventricular (AV) synchrony in maintaining cardiac performance is well established. However, the role of AV synchrony in maintaining adequate Impella output has not been fully evaluated. Despite the common belief that AV dyssynchrony does not affect Impella output, given that Impella is a continuous flow device, recent reports indicate that AV dyssynchrony can lead to low Impella output in patients with cardiogenic shock complicated by complete heart block. Temporary transvenous pacing without establishing AV synchrony may fail to improve Impella hemodynamics; therefore, understanding the mechanism of low Impella output in AV dyssynchrony and promptly restoring AV synchrony may improve Impella output in such cases and lead to better outcomes.
\end{abstract}

Keywords: AV dyssynchrony; Impella output; Cardiogenic shock; Complete heart block; Acute myocardial infarction

\section{Introduction}

Cardiogenic shock (CS) is a complex syndrome that can lead to multiorgan dysfunction and death if not adequately or timely treated [1]. Despite significant advances in therapeutic options, including mechanical circulatory support devices (MCSDs), the management of acute CS continues to be challenging, and clinical outcomes remain poor [2]. Acute myocardial infarction (AMI) accounts for most of the cases of CS with mortality exceeding $40 \%[2,3]$. Intravenous vasopressor and inotropes remain the first-line treatment strategy for the management of CS. However, it is well established that intravenous (IV) vasopressors and inotropes have the propensity to

Manuscript submitted May 28, 2021, accepted June 18, 2021

Published online July 9, 2021

aDepartment of Cardiology, Heart Lung Vascular Institute, University of Tennessee Medical Center, Knoxville, TN, USA

${ }^{b}$ Corresponding Author: Hassan Tahir, University of Tennessee Medical Center in Knoxville, 1924 Alcoa Hwy, Knoxville, TN 37920, USA.

Email: doctorhassantahir@gmail.com

doi: https://doi.org/10.14740/cr1287 increase cardiovascular mortality due to increased myocardial oxygen demand and life-threatening ventricular arrhythmias [4-7]. This has led to the paradigm shift towards the use of MCSDs, which offer the advantage of providing hemodynamic support without worsening myocardial ischemia $[8,9]$. Impella is a novel percutaneous catheter-based ventricular assist device used for maintaining hemodynamic support in CS complicating AMI [10]. Impella has become the MCSD of choice for CS complicated by AMI. Current guidelines recommend the use of MCSD in patients with refractory shock [11]. Recent data suggest that MCSD can improve outcomes in carefully selected patients using standardized treatment algorithms and following best vascular access and closure practices [12-14]. A recent meta-analysis has shown that Impella in AMI complicated by CS may improve survival [15].

\section{Hemodynamics of Impella}

Impella is an intravascular micro-axial pump mounted on a catheter that is advanced across the aortic valve via femoral, axillary or transcaval access [16]. Impella effectively pumps blood from the inlet in the left ventricle (LV) to the outlet in the ascending aorta above the aortic valve. The primary hemodynamic effect of Impella is improved systemic hemodynamics, including an increase in cardiac output, aortic pressure, and cardiac power output (CPO) $[17,18]$. In addition to improving systemic hemodynamics, Impella leads to a significant decrease in right atrial pressure, mean pulmonary artery pressure, pulmonary capillary wedge pressure, and LV end-diastolic pressure [17-19]. Impella also augments coronary blood flow, thereby increasing myocardial oxygen supply [17, 18, 20, 21]. On the other hand, it decreases myocardial oxygen demand by reducing LV wall stress [17]. One study concluded that LV unloading by Impella improves LV end-diastolic compliance and decreases diastolic wall stress [22]. Increased coronary perfusion and decreased coronary microvascular resistance have been reported with Impella in patients requiring high-risk percutaneous coronary intervention (PCI) [23]. Another study has indicated that Impella can increase coronary perfusion pressure in the presence of critical stenosis [24].

Ventricular unloading by Impella leads to a decrease in LV end-diastolic pressure and LV end-diastolic volume, which subsequently leads to a decrease in native LV cardiac output 
Table 1. Factors Reported by Various Studies Which Can Affect Impella Hemodynamics

\begin{tabular}{|c|c|c|c|c|}
\hline Study & Study type & $\begin{array}{l}\text { No. of } \\
\text { patients }\end{array}$ & Type(s) of Impella & Factors \\
\hline $\begin{array}{l}\text { Khalid et } \\
\text { al [26] }\end{array}$ & $\begin{array}{l}\text { Observational, } \\
\text { retrospective study }\end{array}$ & 407 & $\begin{array}{l}\text { Impella CP (53.6\%); Impella } 2.5 \\
(20.1 \%) ; \text { Impella } 5.0(11.5 \%) ; \text { Impella } \\
\text { LD }(0.2 \%) \text {; unspecified }(14.5 \%)\end{array}$ & $\begin{array}{l}\text { Device-related events (damage of } \\
\text { device components, device malfunction, } \\
\text { and device separation) }\end{array}$ \\
\hline $\begin{array}{l}\text { Gaudard } \\
\text { et al [27] }\end{array}$ & $\begin{array}{l}\text { Observational, } \\
\text { retrospective study }\end{array}$ & 40 & Impella 5.0 & $\begin{array}{l}\text { Major device malfunction (device failure), minor } \\
\text { device malfunction (flow, position or pressure } \\
\text { monitoring failure), device malposition (intra-aortic } \\
\text { or intra-left ventricular moving), and bleeding }\end{array}$ \\
\hline $\begin{array}{l}\text { Lemair et } \\
\text { al [28] }\end{array}$ & $\begin{array}{l}\text { Observational, } \\
\text { retrospective study }\end{array}$ & 47 & Impella 5 (80\%); Impella $2.5(20 \%)$ & $\begin{array}{l}\text { Device malfunction (due to kinking or } \\
\text { unknown etiology) and high purge pressures }\end{array}$ \\
\hline $\begin{array}{l}\text { Meyns et } \\
\text { al [29] }\end{array}$ & $\begin{array}{l}\text { Observational, } \\
\text { retrospective study }\end{array}$ & 16 & Impella 2.5 & Device sensor failure and pump displacement \\
\hline $\begin{array}{l}\text { Lauten et } \\
\text { al [30] }\end{array}$ & $\begin{array}{l}\text { Observational, } \\
\text { retrospective study }\end{array}$ & 120 & Impella 2.5 & Device malfunction \\
\hline $\begin{array}{l}\text { Succar et } \\
\text { al [32] }\end{array}$ & Case series & 5 & Impella CP & $\begin{array}{l}\text { Impella thrombosis treated with } \\
\text { tissue plasminogen activator }\end{array}$ \\
\hline $\begin{array}{l}\text { Floyd et } \\
\text { al [33] }\end{array}$ & Case report & 1 & Impella CP & Kinking of catheter due to short stature \\
\hline $\begin{array}{l}\text { Alkhawam } \\
\text { et al [34] }\end{array}$ & Case report & 1 & Impella 5.0 & Right ventricular failure \\
\hline $\begin{array}{l}\text { Hotta et } \\
\text { al [35] }\end{array}$ & Case series & 3 & Impella 5.0 & $\begin{array}{l}\text { New-onset aortic regurgitation } \\
\text { after Impella placement }\end{array}$ \\
\hline
\end{tabular}

[17]. However, total cardiac output is increased due to increased output from Impella $[17,25]$. This indicates that the output generated by Impella is volume-dependent and can be significantly reduced in conditions leading to low LV blood volume. Many factors may affect LV blood volume, and it is extremely important for cardiologists, heart failure specialists, and intensivists who care for patients on Impella to know the factors that cause low Impella output and manage them effectively.

\section{Factors Causing Low Impella Output}

Factors leading to low Impella or failing Impella output can lead to poor organ perfusion, thus increasing morbidity and mortality. There are many factors reported in the literature which can lead to low Impella output (Table 1) [26-35]. Since the Impella is volume-dependent, any cause of low LV volume such as hemorrhage or cardiac tamponade can lead to low or failing Impella output. Rarely, device-related factors can be associated with failing Impella output, such as device dislodgement, fracture or damage of device element, device thrombosis, device detachment, major device malfunction, or pressure monitoring failure [26-30]. Acute thrombosis of Impella catheter can lead to a significant drop or no flow leading to hemodynamic instability [31, 32]. Succar et al reported case series of five patients with suspected Impella thrombosis who were successfully treated with tissue plasminogen activa- tor (tPA) administration [32]. Low Impella output due to kinking of Impella in a patient with short stature has been reported [33]. Another study indicates that right ventricular (RV) failure can sometimes occur following placement of a percutaneous LV assist device and can lead to failing hemodynamics [34]. Rarely, new-onset aortic regurgitation after Impella placement can affect Impella hemodynamics [35].

\section{Does AV Dyssynchrony Affect Impella Hemody- namics?}

AV synchrony plays a vital role in maintaining cardiac output $[36,37]$. In patients with normal LV systolic function, atrial kick contributes to almost $20-30 \%$ of LV stroke volume [38]. However, in patients with severe heart failure, the atrial kick contributes significantly more to stroke volume, and loss of atrial kick can lead to worsening heart failure or shock [39]. The contribution of AV synchrony to improving stroke volume in heart failure patients is well established $[39,40]$. In patients with severely reduced LV systolic function, any improvement in stroke volume from an appropriately timed atrial systole may be beneficial in improving hemodynamics [39, 40]. Improvement in hemodynamics with the restoration of AV synchrony may occur in patients with normal LV function; however, the greater relative improvement in stroke volume and cardiac output is typically seen in those patients with severe LV systolic 
Table 2. Studies Evaluating the Effect of Atrioventricular Dyssynchrony on Impella Hemodynamics

\begin{tabular}{lllll}
\hline Study & Study type & $\begin{array}{l}\text { No. of } \\
\text { patients }\end{array}$ & Type(s) of Impella & Factors \\
\hline Sardana et al [41] & Case report & 1 & Impella CP & Atrioventricular dyssynchrony \\
Tahir et al [42] & Case report & 1 & Impella CP & $\begin{array}{l}\text { Atrioventricular dyssynchrony managed successfully with atrioventricular } \\
\text { sequential pacing resulting in improved hemodynamics and correction of } \\
\text { recurrent ventricular fibrillation }\end{array}$ \\
\hline
\end{tabular}

dysfunction. Although the significance of atrial contribution in increasing cardiac output in patients with severe LV systolic dysfunction is well known, the effect of AV synchrony on Impella hemodynamics is not well established. AV dyssynchrony during Impella hemodynamic support is usually seen in patients with STEMI complicated by CS and complete heart block. Using single chamber temporary pacing may lead to low Impella output in such patients due to continued loss of AV synchrony despite normally functioning Impella. There is a paucity of literature regarding the effect of AV dyssynchrony on Impella hemodynamics (Table 2) [41, 42]. One case of frequent episodes of hypotension despite Impella circulatory support correlating with periods of AV dissociation in the setting of acute LV dysfunction was recently reported [41]. We recently reported a case of low or failing Impella output secondary to AV asynchrony in an acute anterior myocardial infarction patient complicated by complete heart block and CS [42]. Singlechamber pacing led to a significant drop in Impella output [42]. The failing Impella hemodynamics was reversed quickly with AV synchronous pacing using Damato catheter, thus improving outcome [42]. Improved hemodynamics with restoring AV synchrony using coronary sinus pacing with Damato catheter highlights that AV dyssynchrony and loss of atrial kick can lead to poor Impella output [42]. We hypothesized that RA/RV dyssynchrony might have led to a drop in RV output resulting in loss of LV volume and a "low volume-low Impella output syndrome". Loss of LV volume with AV dyssynchrony due to single-chamber pacing in complete AV block can cause a low volume state, which leads to low Impella output. Impella is volume-dependent for maintaining adequate output. One case of RV failure following placement of percutaneous LV assist device leading to failing hemodynamics highlights the importance of adequate RV output in maintaining Impella output [29]. Loss of RA-RV synchrony with single-chamber pacing in complete heart block can lead to low RV output, which can result in "low volume-low Impella output syndrome" as mentioned above. If the cause of low Impella output is low blood volume due to any cause, then increasing volume status will certainly help improving the Impella output. However, increasing volume status would not be helpful in AV dyssynchrony due to lack of atrial contribution to ventricular output. We believe that "low volume-low Impella output syndrome" may not be rare as it can occur in any Impella case complicated by complete heart block or after single-chamber pacing with underlying AV dyssynchrony. There is a paucity of literature regarding this entity, and its physiological mechanisms are poorly understood. Two examples of failing Impella hemodynamics due to loss of AV synchrony in RV paced rhythm from our clinical practice have been shown in Figures 1 and 2. We believe that this entity happens more often than we commonly notice in practice, and there is a paucity of information regarding the role of AV synchrony in maintaining RV output, which the Impella is known to acutely dependent on.

\section{Conclusion}

Loss of AV synchrony can lead to low Impella output, especially in CS patients who undergo single-chamber temporary transvenous pacemaker for complete heart block. The physiological mechanism is poorly understood, although AV dyssynchrony leading to low RV output may perhaps explain the underlying cause as this will result in low LV output despite normally functioning Impella. AV dyssynchrony should be added to the list of factors causing failing Impella hemodynamics, and patients with CS on Impella should have reliable AV synchrony to improve outcomes.

\section{Acknowledgments}

None to declare.

\section{Financial Disclosure}

None to declare.

\section{Conflict of Interest}

None to declare.

\section{Author Contributions}

Raj Baljepally conceived and designed the study. Hassan Tahir and Raj Baljepally did the review of literature and wrote the manuscript. Both authors performed the critical revision of article and approved the final version of manuscript.

\section{Data Availability}

The authors declare that data supporting the findings of this 


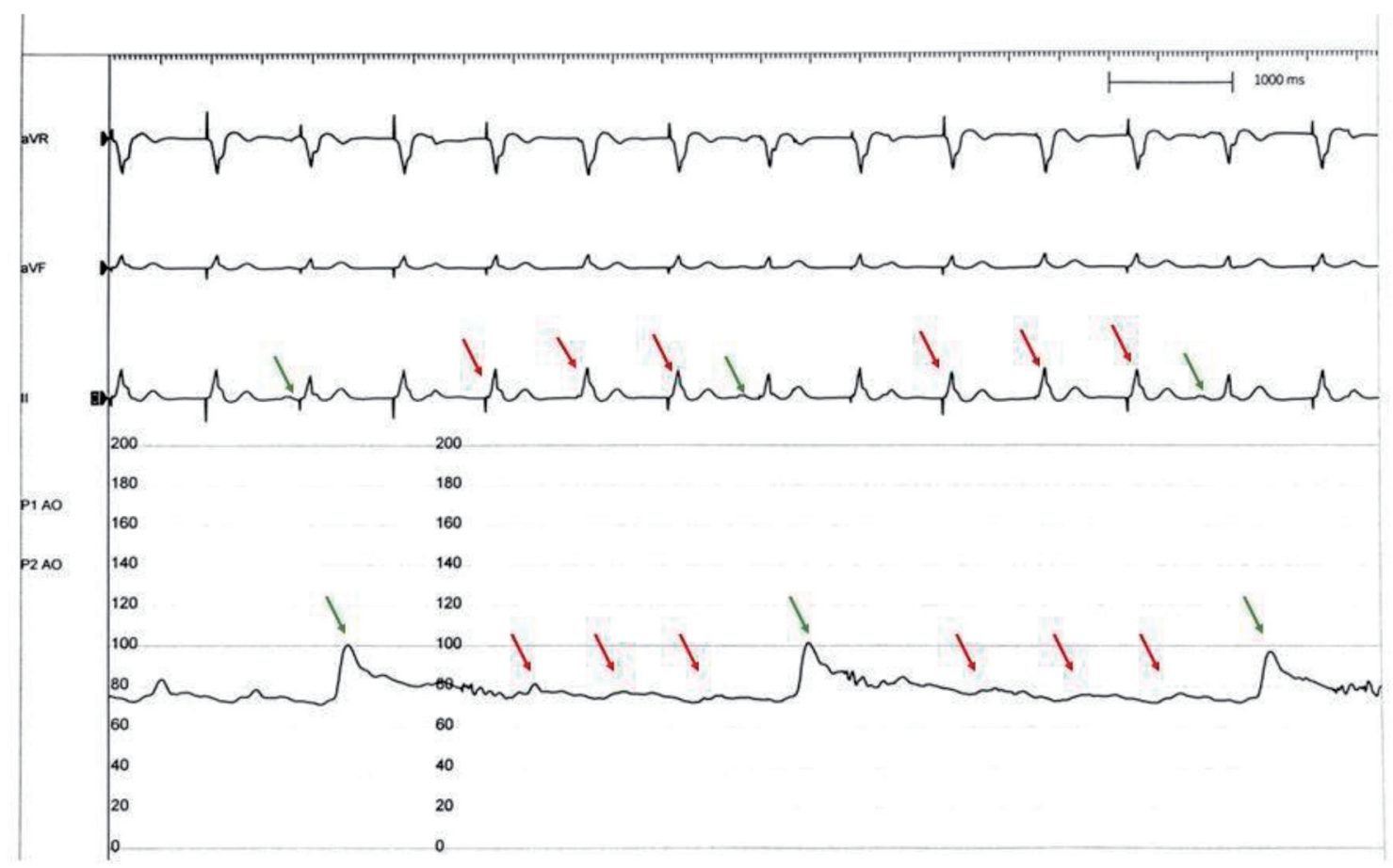

Figure 1. Aortic pressure tracing with Impella mechanical circulatory support device. Intermittent significant drop in aortic pressures seen correlating with loss of AV synchrony (red arrows). Impella output improves significantly in beats with adequate AV synchrony (green arrows). AV: atrioventricular.

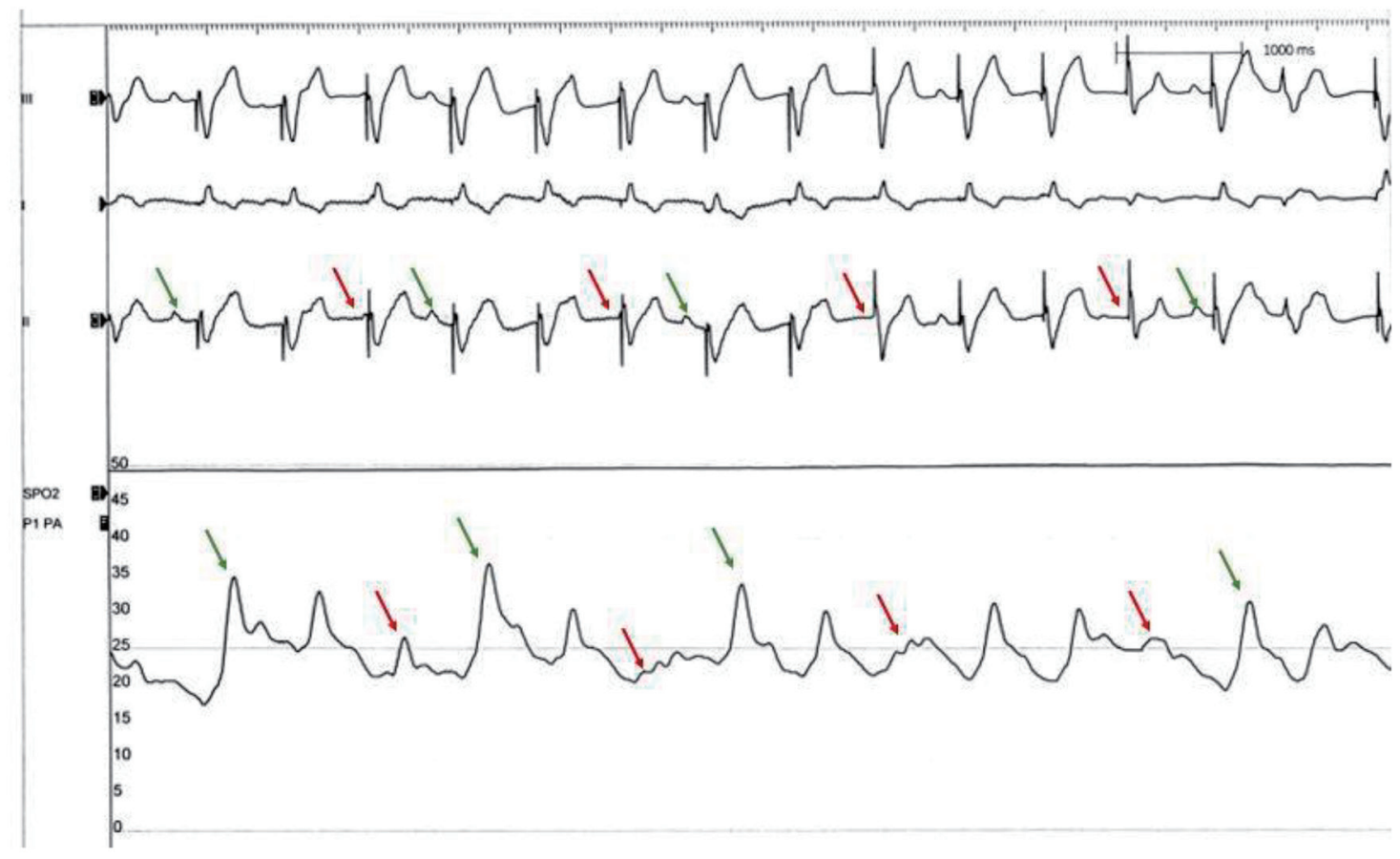

Figure 2. Pulmonary artery pressure tracing with Impella mechanical circulatory support device. Pulmonary artery pressure drops significantly with loss of AV synchrony (red arrows) and improves intermittently with synchronous paced beats (green arrows). This indicates that loss of AV synchrony in single chamber paced rhythm in complete heart block can affect RV cardiac output which can indirectly affect Impella output causing "low volume-low Impella output syndrome". AV: atrioventricular; RV: right ventricular. 
study are available within the article.

\section{References}

1. Reynolds HR, Hochman JS. Cardiogenic shock: current concepts and improving outcomes. Circulation. 2008;117(5):686-697.

2. Hochman JS. Cardiogenic shock complicating acute myocardial infarction: expanding the paradigm. Circulation. 2003;107(24):2998-3002.

3. Goldberg RJ, Samad NA, Yarzebski J, Gurwitz J, Bigelow C, Gore JM. Temporal trends in cardiogenic shock complicating acute myocardial infarction. N Engl J Med. 1999;340(15):1162-1168.

4. Valente S, Lazzeri C, Vecchio S, Giglioli C, Margheri M, Bernardo P, Comeglio M, et al. Predictors of in-hospital mortality after percutaneous coronary intervention for cardiogenic shock. Int J Cardiol. 2007;114(2):176-182.

5. De Backer D, Biston P, Devriendt J, Madl C, Chochrad D, Aldecoa C, Brasseur A, et al. Comparison of dopamine and norepinephrine in the treatment of shock. N Engl J Med. 2010;362(9):779-789.

6. Tarvasmaki T, Lassus J, Varpula M, Sionis A, Sund R, Kober L, Spinar J, et al. Current real-life use of vasopressors and inotropes in cardiogenic shock - adrenaline use is associated with excess organ injury and mortality. Crit Care. 2016;20(1):208.

7. Levy B, Clere-Jehl R, Legras A, Morichau-Beauchant T, Leone M, Frederique G, Quenot JP, et al. Epinephrine versus norepinephrine for cardiogenic shock after acute myocardial infarction. J Am Coll Cardiol. 2018;72(2):173182.

8. Smalling RW, Cassidy DB, Barrett R, Lachterman B, Felli P, Amirian J. Improved regional myocardial blood flow, left ventricular unloading, and infarct salvage using an axial-flow, transvalvular left ventricular assist device. A comparison with intra-aortic balloon counterpulsation and reperfusion alone in a canine infarction model. Circulation. 1992;85(3):1152-1159.

9. Meyns B, Stolinski J, Leunens V, Verbeken E, Flameng W. Left ventricular support by catheter-mounted axial flow pump reduces infarct size. J Am Coll Cardiol. 2003;41(7):1087-1095.

10. Burzotta F, Russo G, Previ L, Bruno P, Aurigemma C, Trani C. Impella: pumps overview and access site management. Minerva Cardioangiol. 2018;66(5):606-611.

11. Antman EM, Anbe DT, Armstrong PW, Bates ER, Green LA, Hand M, Hochman JS, et al. ACC/AHA guidelines for the management of patients with ST-elevation myocardial infarction - executive summary: a report of the American College of Cardiology/American Heart Association Task Force on Practice Guidelines (Writing Committee to Revise the 1999 Guidelines for the Management of Patients With Acute Myocardial Infarction). Circulation. 2004;110(5):588-636.

12. Flaherty MP, Khan AR, O'Neill WW. Early initiation of Impella in acute myocardial infarction complicated by cardiogenic shock improves survival: a meta-analysis.
JACC Cardiovasc Interv. 2017;10(17):1805-1806.

13. O'Neill WW, Schreiber T, Wohns DH, Rihal C, Naidu SS, Civitello AB, Dixon SR, et al. The current use of Impella 2.5 in acute myocardial infarction complicated by cardiogenic shock: results from the USpella Registry. J Interv Cardiol. 2014;27(1):1-11.

14. Basir MB, Schreiber TL, Grines CL, Dixon SR, Moses JW, Maini BS, Khandelwal AK, et al. Effect of early initiation of mechanical circulatory support on survival in cardiogenic shock. Am J Cardiol. 2017;119(6):845-851.

15. Alasnag MA, Gardi DO, Elder M, Kannam H, Ali F, Petrina M, Kheterpal V, et al. Use of the Impella 2.5 for prophylactic circulatory support during elective high-risk percutaneous coronary intervention. Cardiovasc Revasc Med. 2011;12(5):299-303.

16. Glazier JJ, Kaki A. The Impella device: historical background, clinical applications and future directions. Int J Angiol. 2019;28(2):118-123.

17. Weber DM, Raess DH, Henriques J, Siess T. Principles of Impella cardiac support. Cardiac Interventions Today. 2009:3-16.

18. Remmelink M, Sjauw KD, Henriques JP, de Winter RJ, Koch KT, van der Schaaf RJ, Vis MM, et al. Effects of left ventricular unloading by Impella recover LP2.5 on coronary hemodynamics. Catheter Cardiovasc Interv. 2007;70(4):532-537.

19. Khan MH, Corbett BJ, Hollenberg SM. Mechanical circulatory support in acute cardiogenic shock. F1000Prime Rep. 2014;6:91.

20. Aqel RA, Hage FG, Iskandrian AE. Improvement of myocardial perfusion with a percutaneously inserted left ventricular assist device. J Nucl Cardiol. 2010;17(1):158160.

21. Sauren LD, Accord RE, Hamzeh K, de Jong M, van der Nagel T, van der Veen FH, Maessen JG. Combined Impella and intra-aortic balloon pump support to improve both ventricular unloading and coronary blood flow for myocardial recovery: an experimental study. Artif Organs. 2007;31(11):839-842.

22. Remmelink M, Sjauw KD, Henriques JP, de Winter RJ, Vis MM, Koch KT, Paulus WJ, et al. Effects of mechanical left ventricular unloading by Impella on left ventricular dynamics in high-risk and primary percutaneous coronary intervention patients. Catheter Cardiovasc Interv. 2010;75(2):187-194.

23. Ouweneel DM, Claessen BE, Sjauw KD, Henriques JP. The Role of Percutaneous Haemodynamic Support in High-risk Percutaneous Coronary Intervention and Cardiogenic Shock. Interv Cardiol. 2015;10(1):39-44.

24. Alqarqaz M, Basir M, Alaswad K, O'Neill W. Effects of Impella on coronary perfusion in patients with critical coronary artery stenosis. Circ Cardiovasc Interv. 2018;11(4):e005870.

25. Dixon SR, Henriques JP, Mauri L, Sjauw K, Civitello A, Kar B, Loyalka P, et al. A prospective feasibility trial investigating the use of the Impella 2.5 system in patients undergoing high-risk percutaneous coronary intervention (The PROTECT I Trial): initial U.S. experience. JACC Cardiovasc Interv. 2009;2(2):91-96. 
26. Khalid N, Rogers T, Shlofmitz E, Chen Y, Khan JM, Musallam $\mathrm{A}$, Iantorno $\mathrm{M}$, et al. Adverse events and modes of failure related to the Impella percutaneous left ventricular assist devices: a retrospective analysis of the MAUDE database. EuroIntervention. 2019;15(1):44-46.

27. Gaudard P, Mourad M, Eliet J, Zeroual N, Culas G, Rouviere P, Albat B, et al. Management and outcome of patients supported with Impella 5.0 for refractory cardiogenic shock. Crit Care. 2015;19:363.

28. Lemaire A, Anderson MB, Lee LY, Scholz P, Prendergast T, Goodman A, Lozano AM, et al. The Impella device for acute mechanical circulatory support in patients in cardiogenic shock. Ann Thorac Surg. 2014;97(1):133-138.

29. Meyns B, Dens J, Sergeant P, Herijgers P, Daenen W, Flameng W. Initial experiences with the Impella device in patients with cardiogenic shock - Impella support for cardiogenic shock. Thorac Cardiovasc Surg. 2003;51(6):312317.

30. Lauten A, Engstrom AE, Jung C, Empen K, Erne P, Cook $\mathrm{S}$, Windecker S, et al. Percutaneous left-ventricular support with the Impella-2.5-assist device in acute cardiogenic shock: results of the Impella-EUROSHOCK-registry. Circ Heart Fail. 2013;6(1):23-30.

31. Ranc S, Sibellas F, Green L. Acute intraventricular thrombosis of an impella LP 5.0 device in an ST-elevated myocardial infarction complicated by cardiogenic shock. J Invasive Cardiol. 2013;25(1):E1-3.

32. Succar L, Donahue KR, Varnado S, Kim JH. Use of tissue plasminogen activator alteplase for suspected Impella thrombosis. Pharmacotherapy. 2020;40(2):169-173.

33. Floyd J, Naji P. Unusual cause for low impella output: kinking of impella in a patient with short stature. J am coll cardiol. 2020;75(11):2789.

34. Alkhawam H, Rafeedheen R, Abo-Salem E. Right ventricular failure following placement of a percutaneous left ventricular assist device. Heart Lung. 2019;48(2):111-113.

35. Hotta N, Tsukinaga A, Yoshitani K, Ohnishi Y. Pitfalls of anesthetic management with the Impella(R) 5.0 device: a case series. JA Clin Rep. 2020;6(1):21.

36. Connolly SJ, Kerr C, Gent M, Yusuf S. Dual-chamber versus ventricular pacing. Critical appraisal of current data. Circulation. 1996;94(3):578-583.

37. Wong GC, Hadjis T. Single chamber ventricular compared with dual chamber pacing: a review. Can J Cardiol. 2002;18(3):301-307.

38. Namana V, Gupta SS, Sabharwal N, Hollander G. Clinical significance of atrial kick. QJM. 2018;111(8):569-570.

39. St John Sutton M, Cerkvenik J, Borlaug BA, Daubert C, Gold MR, Ghio S, Chirinos JA, et al. Effects of cardiac resynchronization therapy on cardiac remodeling and contractile function: results from resynchronization reverses remodeling in systolic left ventricular dysfunction (REVERSE). J Am Heart Assoc. 2015;4(9):e002054.

40. Schuchert A, Aydin MA, Israel C, Gaby G, Paul V. Atrial pacing and sensing characteristics in heart failure patients undergoing cardiac resynchronization therapy. Europace. 2005;7(2):165-169.

41. Sardana M, Shaikh A, Smith C. The atrial kick: atrioventricular dyssynchrony causing paroxysms of hypotension in setting of acute left ventricular dysfunction. Journal of the American College of Cardiology. 2018;71(11):10-12.

42. Tahir H, Tonks R, Cox J, Baljepally R. Optimizing mechanical circulatory support hemodynamics using coronary sinus pacing. Catheter Cardiovasc Interv. 2021:1-7. 